\title{
Ética e Relações Internacionais: elementos de uma agenda político- cultural
}

\section{ESTEVÃO DE REZENDE MARTINS*}

As relações políticas em geral e as internacionais em particular são, habitualmente, consideradas isentas de julgamentos com base em critérios éticos. A moralidade - ao menos tradicionalmente - parece (ou ao menos parecia) ser instância exclusiva de ajuizamento de comportamentos particulares, individuais, de foro íntimo. A evolução histórica evidencia, contudo, que vem crescendo a exigência pública de observância de regras aplicáveis ao espaço público sem exceções. A teoria política e a historiografia correspondente vêm ecoando essa tendência, em particular desde a década de 1990, no marco da mudança de era simbolizada pela queda do muro de Berlim. Como se chegou a esse ponto? Pode-se fornecer alguns elementos de resposta. Um, o itinerário da concepção teórica da questão ética nas relações internacionais (mui diversa de sua prática). Outro, o papel normativo (inicialmente abstrato, depois de 1945 mais prático) dos direitos humanos e das liberdades fundamentais, incluindo o padrão da democracia liberal como forma política da organização social. Um terceiro, enfim, a (historicamente) rápida evolução de certos blocos regionais, exemplificada pela União Européia. Preliminarmente importa circunscrever o "meio ambiente" político em que a questão se põe, no plano internacional, e sua recepção interna no Brasil.

\section{Direitos humanos como eixo categorial da "agenda ética"}

A "agenda ética" no plano das relações inter-estatais dos anos 1990 em diante organizou-se primeiramente em torno da declaração universal dos direitos humanos de 1948. O hiato de iniciativas notáveis durante cerca de quatro décadas não tem sido objeto de análise detida ou de explicação consistente. O leque de sucessivas declarações adotadas ao longo desse período corresponde a desdobramentos dos enunciados - anteriormente formulados - dos assim chamados direitos de primeira e segunda geração, concentrados nos campos individual, político e social. 
As condições concretas da cena política internacional, impregnadas da lógica da guerra fria, acarretaram um determinado grau de ineficácia de tantas declarações. A dimensão de cunho retórico que pareceu envolver e, de certa maneira, neutralizar as macro-declarações de alcance planetário (ao menos teoricamente), levou à regionalização - não raro repetitiva - das declarações de direitos. ${ }^{1}$ Pode-se distinguir, dessarte, uma dupla atitude política na gestão internacional dos direitos fundamentais. De um lado, mantém-se o tema na ordem do dia desses quarenta anos como um recurso basicamente teórico. Esse recurso evita a eventual crítica - interna e externa - de o tema dos direitos haver sido banido da agenda. Por outro lado, ao se examinar o comportamento político dos governos, constata-se que o uso do discurso enunciativo dos direitos e dos valores - em declarações, convenções e protocolos - serviu de biombo para encobrir o pragmatismo inter-estatal nas relações sobretudo econômicas. ${ }^{2}$ A legislação estadunidense sobre direitos humanos, dos anos 1970, afinal gerou meros condicionantes de ajuda econômica, com poucos efeitos na matéria mesma, como se pôde constatar nas alianças políticas - abertas ou veladas - entre o governo dos Estados Unidos e o de países latino-americanos como, por exemplo, o Brasil, a Argentina ou o Chile.

A modificação estrutural das relações políticas iniciadas com desmoronamento do bloco soviético recoloca na agenda internacional não apenas declarações enquanto tais, mas sua aplicação e prática. É nesta perspectiva que a ONU reuniu em Viena, em junho de 1993, na conferência mundial sobre direitos humanos, um tabuleiro estatal com nova geometria política. ${ }^{3}$ Essa conferência sucedeu a uma outra, sobre o meio-ambiente e o desenvolvimento sustentável (Rio 92), igualmente representativa de uma alteração substantiva do quadro das relações inter-estatais, no qual doravante a qualidade da vida individual e social tornou-se um fator de primeira ordem e não mais uma variável secundária.

A conferência de Viena buscou sistematizar a agenda internacional na passagem do longo itinerário teórico para uma prática enfim considerada urgente, vale dizer, um valor normativo a ser observado como pauta comportamental de indivíduos e de governantes. A generalidade dos direitos - que se pretendem universais e que como tais são reafirmados em acelerado movimento globalizante - ganha uma roupagem particularizada, na medida em que a cada estado é posta a exigência moral pública de os realizar, independentemente de questões de soberania. ${ }^{4} \mathrm{O}$ espaço ético é, no entanto, ainda mantido no plano da autodeterminação de cada estado, sem que tenha produzido, na conferência, uma análise prudente da herança oitocentista do modelo dos estados-nações. Entretanto o reconhecimento, por uma instância princeps de negociação multilateral, de que há um denso programa político de ação internacional para a efetivação dos direitos humanos (civis, políticos, sociais) - como tarefa ética - é um avanço não 
negligenciável. Esse reconhecimento inclui setores cujo pragmatismo punha de lado a questão dos direitos. Assim, entra no vocabulário internacional o caráter ético da conciliação entre iniciativa econômica, políticas públicas (internas e externas), desenvolvimento social e consolidação democrática, como põe em evidência Lindgren Alves, com destaque para a política brasileira de defender ações afirmativas multilaterais nessa matéria, malgrado as hesitações dos processos decisórios. ${ }^{5}$ Deu-se nesse ponto um notável passo adiante na conformação do modelo comportamental que se quer ver adotado na gestão pública. A política e a prática dos valores, reclamo tradicional e constante dos movimentos sociais, não raro apesar dos governos e mesmo contra eles, passam a integrar o ethos ilustrado de uma globalização econômica e financeira, cujos efeitos cabe temperar. Essa perspectiva não pode ser, segundo Celso Lafer, pretexto para dividir o mundo entre observantes e infratores da agenda ética, pois é da responsabilidade política coletiva da comunidade dos estados. ${ }^{6}$

O estado brasileiro não deixa, pois, escapar o tríptico político dos direitos, da economia e dos valores. Prevalece, por certo, a busca de uma posição do Brasil - o mais segura possível - no novo mundo da competência produtiva e da concorrência qualitativa. ${ }^{7}$ Lampreia indica o quanto a posição brasileira evoluiu do reconhecimento abstrato e inercial dos direitos universais desde os anos 1940 (sem deter-se na difícil fase do período autoritário) para uma atitude preeminente de iniciativa própria, a contar notadamente da redemocratização do país da segunda metade dos anos 1980. Com a ratificação sucessiva de diversos instrumentos internacionais e com uma atuação crescente nos foros multilaterais, o Brasil colocou no topo da agenda de referência de sua política interna e externa o trinômio valorativo - vale dizer, de cunho ético - da democracia, do desenvolvimento e dos direitos humanos.

A questão foi acompanhada de uma ampla discussão teórica e de um percurso político em ritmo acelerado nos anos 1990, de que podem ser extraídos os elementos de resposta a que se fez referência mais acima.

\section{A evolução teórica recente}

Em 1977, Hedley Bull, em The Anarchical Society, ${ }^{8}$ ao sistematizar as três grandes linhas de pensamento que orientam as relações internacionais, de certo modo antecipa a "cobrança" contemporânea de ética na política. A distinção estabelecida para o itinerário dos estados modernos trata (1) da tradição realista, de cunho hobbesiano, que considera a política internacional como a arte da guerra; (2) da tradição internacionalista, de inspiração grociana, que enfatiza a cooperação e a concorrência regulada entre estados soberanos; e (3) da tradição universalista, fundamentada no pensamento kantiano, que busca ver na política internacional a 
atuação (e a realização) da comunidade potencial da humanidade e a efetivação da regra da solidariedade. É voz corrente, na literatura pertinente, que as duas primeiras fórmulas, em grau mais ou menos forte, predominaram até meados do século 20. A terceira fórmula, precedida por diversos intentos até a instalação da ONU, vem fazendo seu caminho ao longo da segunda metade do século 20. Referindo-se a essa visão internacionalista - e por isso mesmo antropocêntrica do formato que as relações políticas parecem vir assumindo nos últimos decênios, Antonio Cassese lembra a crise institucional que as ações terroristas dos anos 1970-1980 provocaram. Dos impasses da violência se construiu a convicção política de ser necessária a cooperação, a integração, a convergência (por vezes a sã concorrência) das instituições internacionais (e de suas versões regionais, como no caso da União Européia) com as iniciativas cidadãs. Dessa integração surgiriam instrumentos para colocar em prática "valores e exigências mais 'humanos', sem minar o sistema atual de estados soberanos ...". 9

Essa questão não é - nem foi -, obviamente, pacífica. Embora a noção de "sociedade anárquica" não se identifique com "sociedade caótica" para os realistas, o pragmatismo de objetivos não é suficiente para lidar com a complexidade da sociedade contemporânea e com a variedade de interesses que os movimentos sociais exprimem. Um dos principais arquitetos da guerra fria à americana, George F. Kennan, ao escrever, em meados dos anos 1980, sobre "moralidade e relações exteriores", insiste na perspectiva centrada no estado, que teria de defender: a "obrigação primária [de um governo] é para com os interesses da sociedade nacional que representa, não para com impulsos morais experimentados por indivíduos dessa mesma sociedade". ${ }^{10}$ Hans Morgenthau já havia, em 1952, contraposto dois modelos de moralidade. Um, utilitarista, plenamente compatível com a teoria realista de política. Outro, transcendental, associado ao que chama ainda de utopia ou de universalismo, com uma ligeira tendência a desqualificar sua viabilidade. ${ }^{11}$

A evolução dos anos 1990 parece encaminhar-se, contudo, na direção de uma crítica dura ao realismo pragmático e utilitarista do sistema interestatal e intergovernamental. A representação dos interesses nacionais que os governos assumem (ou que se afirma terem de assumir, por definição), parte de dois pressupostos fundamentais. Um é a legitimidade da investidura político-institucional. Inexistindo o mecanismo democrático do sufrágio universal, a contestação da legitimidade é crescente. A formalidade da investidura (como no caso dos regimes autoritários ou francamente ditatoriais), embora satisfaça a postura "realista", frustra cada vez mais as opiniões públicas. O outro pressuposto é o de que governos têm de gerir o interesse coletivo em termos universalizantes. Vale dizer: não governar apenas para a maioria que o tenha guindado ao poder, ${ }^{12}$ mas em nome e na perspectiva da sociedade como um todo - sobretudo quando os sistemas eleitorais, em particular os majoritários e os proporcionais simples, tendem a transformar em 
maioria parlamentar de iure a minoria eleitoral de facto, questão problemática para o funcionamento da democracia representativa. Tarefa árdua e interpretação difícil, sem dúvida historicamente condicionadas, conquanto não submetidas a determinismos. No choque entre expectativa valorativa, quadro jurídico-institucional concreto e gestão pragmática do quotidiano revela-se, no longo prazo, a presente tendência do reclamo "moralizante".

A década de 1990 reforçou o entendimento - enfraquecido por meio século de tensões ${ }^{13}$ - de que vivemos doravante numa cultura que não mais admite derrogações à proclamação de ser a pessoa humana detentora de uma dignidade essencial específica, cujo valor se sobrepõe a quaisquer circunstâncias políticas, econômicas e sociais. Essa certeza coletiva entrementes profundamente enraizada inclui a concepção de que o homem em sociedade tem, no respeito dos demais, a garantia da consideração por sua dignidade própria. E de que o entendimento mútuo na defesa da vida, da liberdade, da honra, da imagem, da educação, da saúde, do trabalho e do lazer é penhor de vigência, na justa relação social e política, do valor superior do ser humano e de sua comunidade.

Parafraseando o imperativo categórico da Fundamentação da Metafísica dos Costumes (1785) do filósofo alemão Immanuel Kant (1724-1804), ${ }^{14}$ aceita-se como coerente com a natureza humana o princípio expresso pelo provérbio "não faça aos outros o que não queres que te façam" - pessoal e coletivamente. Assim, a obrigação ética com relação a valores aceitos pelas pessoas, por suas sociedades e por seus Estados é o fundamento da obrigação legal referente às regras formais em vigor. A legitimidade da consciência social e a soberania da vontade geral da sociedade são a origem do efeito coercitivo da regra legal, da norma efetiva, mas decerto não se esgotam nele. Exige-se ter presente um valor decisivo: a regra vale igualmente para todos, sem qualquer outra exceção possível do que aquela que, eventualmente, a totalidade social tenha aceitado fixar - especialmente pelos mecanismos das decisões majoritárias na democracia representativa e participativa.

Há, entretanto, conflito claro entre a impessoalidade da regra e a prática, corrente, da defesa militante de interesses de grupos - sejam eles políticos, sociais, econômicos, religiosos ou culturais. O realismo político, tão decantado por comentaristas e pragmáticos, não raro é invocado como pretexto para escamotear quaisquer obrigações de referência ética e para promover a adoção formal de arcabouço legal e a prática administrativa instrumentalizadas. A noção de moral ou de ética habitualmente utilizada está, todavia, fortemente marcada por conteúdos religiosos, por formas jurídicas ou por doutrinas filosóficas historicamente determinadas. Pode-se dar como exemplo a ética do bom comportamento que acarreta a salvação eterna ou o uso das declarações dos direitos humanos como referência para ingerência ou intervenção. 
A oposição entre ética e Realpolitik é, pois, costumeira. Parece contudo cada vez mais difícil manter uma distinção estanque. Pode a ética eximir-se de levar em conta as realidades e estas podem efetivamente ignorar a dimensão moral da política exterior, em uma época em que a opinião pública desempenha um papel cada vez mais importante na determinação da diplomacia? Vêem-se bem, hoje em dia, os avanços realizados em uma etapa na qual uma justiça internacional, por hesitante que seja, se instaura e se instala. É certo que ainda existem ditadores (e quem poderá garantir que nunca mais os haja, mesmo se o desejo coletivo é esse?). Mas estes já não estão plenamente garantidos de ficar impunes em nome de uma inviolabilidade acrítica das garantias clássicas da soberania estatal e do asilo político. Curiosamente, A. Watson menciona apenas a noção de "suserania" como um conceito restrito às relações de poder na Europa medieval e não recorre ao conceito de "soberania" como legitimador clássico da autoridade estatal. ${ }^{15}$

Intervenções coletivas de conjuntos de estados sob invocação de determinado caráter humanitário representam a modificação conceitual do direito de ingerência, em contraposição à sacrossanta soberania dos estados-nações. Não resta dúvida de que a fase em que nos encontramos é de transição e de incerteza, de insegurança e de busca. Tampouco os direitos humanos, individual e coletivamente, chegaram a um ponto ótimo de aplicação. Mas constata-se progressos notáveis ao longo da segunda metade do século 20. E certa aceleração nos últimos dez anos.

Essa constatação indica um fator cultural presentemente em evolução. O que parece ter sido, no passado, um moralismo de fachada, vem-se mantendo na agenda política pública como uma assim chamada "cobrança das bases" ou balanço da "dívida social", intranacional ou internacional, a ser resgatada por políticas públicas. A difusão cultural da autovalorização social dos agentes privados como, por exemplo, as organizações não-governamentais - termo que designa, para além da classificação gerencial da Organização das Nações Unidas, já há alguns anos associações de interesse político-social que exprimem novos setores de atuação coletiva e representam uma visão cultural da sociedade como conjunto supranacional de agentes racionais desvinculados de obrigações para com decisões celeradas ou duvidosas. Assim, há os movimentos contrários à disseminação da energia nuclear (mesmo após a corrida armamentista e o recuo da ameaça atômica), a convergência de associações de militância anti-racista, a defesa da preservação do meio-ambiente equilibrado e sustentado, as ações humanitárias transnacionais de saúde (como, por exemplo, a dos Médicos Sem Fronteiras e análogas), e inúmeras outras. Constata-se mesmo uma evolução no perfil e no comportamento de instituições tradicionais, sob pressão da mudança do conjunto político internacional, como as ligadas às igrejas (por exemplo, Conselho Mundial das Igrejas) e à assistência sanitária (por exemplo, a Cruz Vermelha Internacional). 
No mundo contemporâneo, essa evolução resultou em uma fórmula chamada de mista por Hubert Védrine, ministro francês das relações exteriores desde 1997: “C'est pourquoi, ... pour des raisons où la morale a toute sa place, et au nom de l'éthique de responsabilité qui m'inspire dans mes fonctions, j'estime que la seule voie constructive est de travailler à une synthèse des aspirations éthiques et des exigences de la realité, de réfléchir aux unes et aux autres en tenant compte non seulement de nos convictions, mais aussi des messages et des avis venus du monde entier" [grifos meus]. ${ }^{16}$ Jean-Claude Casanova afirma que esse enunciado dá uma feição realista a uma política de inspiração idealista. Tal perspectiva inclui o respeito aos direitos humanos, o desenvolvimento da democracia liberal (de início representativa, entrementes mais e mais participativa), a similitude ou proximidade das opiniões, o contacto e o intercâmbio culturais, o incremento do comércio e tantos outros fatores que colocam em evidência crescente que, hoje, vive-se muito mais sob o olhar do outro do que em épocas passadas. ${ }^{17}$

É certo que essa visão do mundo tem de ser gerida sob as circunstâncias concretas da história empírica da atualidade, originada, proximamente, ao longo da segunda metade do século 20 . Hoje, tais exigências têm de levar em conta, imediatamente, o papel preponderante dos Estados Unidos na configuração política, econômica e comercial do planeta. Progresso da normalização jurídica inclui indubitavelmente algum tipo de sistema de sanções, do contrário o discurso sobre a moral poderia não passar de recurso de retórica ou, pior, cortina de fumaça. Casanova endurece o tom, ao dizer que a reforma e a modernização das normas internacionais têm de ser efetivamente assumidas - no caso de sua tese, pelas Nações Unidas, inclusive quanto aos termos da Carta da Organização. A opinião pública - nacional ou internacional, na medida em que o 'nacionalismo de opinião', equivalente ao argumento restritivo da validade territorial, perde espaço - exige insistentemente que se ultrapasse a mera retórica eleitoral e que os indivíduos investidos na responsabilidade política de gestão, que repetidamente falam de "progressos da moral, progressos do direito", provem-no pelos atos.

Que atos podem ser estes, que instrumentos estariam à disposição dos dirigentes e dos dirigidos? Uma das vertentes mais marcadas da evolução recente é a acelerada tomada de consciência e as iniciativas dos "dirigidos". É possível discutir - como o fez Antonio Ermírio de Moraes em artigo de opinião na Folha de São Paulo de 15 de julho de $2001^{18}$ - se os "dirigidos" deixam essa condição, ao formarem as entrementes renomadas "organizações não-governamentais". Antonio Ermírio parece lamentar que o entusiasmo com que os Estados receberam a proliferação de ONGs e a liberalidade com que as apoiaram tenham acarretado uma certa frouxidão nos laços formais que deveriam hierarquizar as relações entre ambas as esferas. Esta é, certamente, mais uma faceta da questão cuja multiplicidade e complexidade já requer exame histórico. A passagem de uma 
forte desconfiança do Estado - e de suas variantes multilaterais - a uma "tolerância" neutralizadora de eventuais efeitos indesejados para se chegar, enfim, a uma verdadeira transferência de tarefas - tradicionalmente estatais - para associações de cidadãos, é um percurso que interessa à pesquisa histórica tanto como à análise econômica da "terceirização" dos deveres clássicos do Estado.

O presidente da Comissão de Relações Exteriores da Assembléia Nacional Francesa, François Fillon, ao declarar que "a moral não é a alternativa para a política”, que ela é um de seus componentes, ${ }^{19}$ reconhece que a distinção entre dirigentes e dirigidos está cada vez mais enfraquecida. Responsabilidade e realismo compõem-se para formar um bloco inspirador de decisões cujo sintetizador seria o "princípio humanitário". Esse princípio estaria expresso por dois princípios norteadores da ação da União Européia: o princípio da solidariedade e o princípio da subsidiaridade. A lógica desses princípios já não é mais a da fidelidade a pactos ou alianças de cunho militar. A solidariedade é sobretudo política (e, por extensão, ética) e a subsidiaridade, econômica. É certo que os aspectos estratégicos, na década de 1990, adquiriram uma versão econômica e comercial sem similar com os períodos anteriores. Essa dualidade, posta em termos morais, embora a expressão não apareça, é bem retratada, para o caso de Portugal na União Européia, por Maria Manuela Tavares Ribeiro: "Não estaríamos nós a nos confrontar, hoje, com "duas Europas"? Uma Europa da produtividade, da acumulação, na qual subsiste a desigualdade das riquezas, do bem estar, das diferenças sociais, na qual o "ideal federalista" pareceria funcionar como um mecanismo de aproximações? Sob a ameaça de certo tipo de fusão, assim percebida por muitos portugueses, exorcisase o federalismo no debate público, que dá ênfase ao caráter fundamental da "participação das sociedades, dos cidadãos, dos parlamentos nacionais na construção européia, que continuaria a mesma, mesmo se exigisse um processo de decisão mais lento" (João de Deus Pinheiro). ... A outra Europa é a herdeira política da Revolução francesa, uma Europa dos povos, uma Europa dos cidadãos, da solidariedade internacional, da identidade e da diversidade culturais". ${ }^{20}$

No campo econômico, como conciliar modernização e livre concorrência? As duas não são, porém, incompatíveis. Pelo contrário, trata-se de determinar regras comuns que forneçam um quadro comum e regras do jogo aceitas por todos. Critica-se por vezes os países ocidentais de celebrar acordos comerciais com estados não-democráticos. Será assim uma questão simples, quando ainda em 2000 viu-se dissidentes chineses solicitar que os Estados Unidos não interrompessem o comércio com a China com a mera remissão à questão dos direitos humanos? Como lutar eficazmente contra os fenômenos da lavagem de direito, de desvio de recursos, de corrupção? Como evitar o "dumping social"? Essas são algumas das questões que interessam cada vez mais intensamente os fóruns multilaterais de negociação trabalhista e comercial, como a OIT e a OMC. 
Também no mundo empresarial, princípios éticos são cada vez mais proclamados: proibição do trabalho infantil, respeito dos direitos individuais e coletivos no país ou nos países em que a empresa estiver em atividade, luta contra a corrupção. Aqui também se pode estimar que a situação está longe de ser perfeita, mas o caminho percorrido desde o fim da $2^{\mathrm{a}}$ Guerra Mundial não é negligenciável. $\mathrm{O}$ respeito de normas éticas e de normas sociais - mesmo se ainda de forma fragmentária, sobretudo conforme a região do mundo - vem-se tornando ponto constante das agendas nacionais, internacionais e transnacionais do empresariado. A dissociação entre mundo dos negócios e vulnerabilidade ética dos decisores políticos vem aumentando. Poder-se-ia mesmo dizer que se estaria diante de uma evolução de paradigma. O mecanismo dos grupos de pressão, de lobby a qualquer preço, para obter vantagens dos sistemas de decisão - notadamente dos governos e de seus agentes - por ameaça política ou econômica, financeira ou comercial, embora ainda longe de ter desaparecido, parece estar sob forte pressão da opinião pública para mudar de métodos e tornar-se transparente.

Certas questões relativas à problemática da ética nas relações internacionais parecem prementes. A primeira, certamente, é saber se, no domínio particular da relação entre ética e política exterior, países, governos ou blocos regionais têm um papel específico a desempenhar. No quadro bipolar até recentemente prevalecente, a Europa (mais precisamente a União Européia e suas formações antecessoras) buscou emergir como instância alternativa de política, de gestão e de economia. Desde o desequilíbrio do que se poderia chamar de sistema de Yalta-Potsdam, dividido na equação americano-soviética e longamente simbolizado pelo Muro de Berlim, em benefício - sem contraponto - do pólo americano, a Europa ganhou mais espaço de atuação. Busca intencionalmente perfilar-se como alternativa credível e eficaz. Inclusive no plano militar, com penetração mais forte no sistema decisório da Organização do Tratado do Atlântico Norte.

O tema das novas formas de guerra aparece também como decisivo. Desde a guerra do Golfo, em janeiro-fevereiro de 1991, motivada claramente pelo duplo fator geostratégico da economia do petróleo e da rede de segurança representada pelas bases militares, vem-se encontrando - tanto no discurso como na ação - o recurso à motivação humanitária. Estaríamos diante de uma evolução cultural, que impregnaria as instâncias governamentais nacionais e supranacionais, em direção à guerra em nome dos direitos humanos. Parece paradoxal sustentar a teoria da guerra com "zero mortos" (militares) e infligir a populações civis (por certo indefesas ou incomparavelmente mal aparelhadas) sofrimentos e destruição desmesurados. Neste ponto também se encontra uma evolução dos termos do debate, pois, anteriormente, atingir as populações civis do estado inimigo era plenamente admitido pelas opiniões públicas das partes diretamente envolvidas. Ora, desde a intervenção no Kosovo (e, em menor escala, nos conflitos anteriores na ex-Iugoslávia), tem-se 
um crescente movimento de opinião pública nas sociedades dos países vinculados à OTAN exigindo que as ações de intervenção, em princípio destinadas a salvar uns, não significassem, afinal, a condenação dos outros. Assim, a crítica que se fazia às exações das tropas e das milícias sérvias volta-se também agora contra as exações cometidas pelos resistentes kosovares.

Casanova destaca que inúmeras análises contemporâneas põem em evidência uma moralização progressiva das relações internacionais nos últimos dez anos. Com efeito, os anos 1990 testemunham dois fatos: de uma parte, uma crescente exposição dos processos decisórios das políticas exteriores e das ações concertadas à crítica social generalizada e, de outro, um controle estensivo das normas de direito. Com efeito, constata-se que a invocação de princípios morais, o apelo ao direito internacional - e a sua vigência supranacional - e os argumentos éticos na prática jurídica se tornaram mais freqüentes nos últimos dez anos ou algo mais. É certo que a fase da guerra fria e do mundo 'bipolar' parecia ser mais 'realista' e permitir uma qualificação 'maniqueísta' das ações e políticas. $\mathrm{O}$ desequilíbrio foi introduzido nas relações internacionais ao longo dos anos noventa, pela prevalência, doravante sem concorrentes notáveis, dos Estados Unidos. Essa assimetria contrasta com a inércia política do cenário internacional. Tal cenário está acostumado - se não treinado - a lidar com opções simples (ou simplistas) do gênero: quem não está comigo está contra mim, desde o término da $2^{\mathrm{a}}$ Guerra Mundial. Ela contrasta igualmente, em prazo mais longo, com os ordenamentos internacionais regularmente ditados pela lógica das vitórias militares (e de seus desdobramentos econômicos e comerciais) expressos simbolicamente na assim chamada tríade dos "vês": Vestfália, Viena, Versalhes, fortemente responsável pelo ordenamento político e pela assim chamada hierarquia ocidental das relações entre os estados modernos consolidados. Como sintetiza A. Watson: "The now and non-discriminatory global society was not brought into being a radical break with the past, but a explained ... it has inherited its organization and most of its concepts from its European predecessor. There was a conscious effort after the Second World War to maintain a continuity with the existing rules and institutions, including even the League of Nations; and the League was itself an extension, with some modifications, of the principles and practices developed in the very different context of the European grande république." 21

É duvidoso que se possa qualificar essa evolução, necessariamente, como progresso. Pouco importa. Que se qualifique como progresso, regresso ou estagnação, o que não se pode é, por certo, ignorá-la. A preeminência estadunidense e a ainda não consolidada "alternativa européia" - na medida em que a construção da política externa (e de segurança) comum da União Européia começou a ser colocada em prática justamente nessa mesma fase - indicam que há vulnerabilidades no sistema de crítica e controle (como no de implantação e equilíbrio) 
das políticas públicas manifestamente pressionadas pelo peso específico dos Estados Unidos.

Gilberto Dupas, tratando das difíceis relações éticas na estrutura de poder da sociedade informacional, retoma a questão, em termos nitidamente filosóficos, tal como abordada por Castells. ${ }^{22}$ A consideração do problema ético ao longo de muitos séculos o tomou como matéria de estrito foro íntimo. A ética tradicional tornou-se o padrão do indivíduo isolado, autônomo, responsável, autor de seus próprios princípios, sem referir-se a autoridade exterior. A responsabilidade particular da pessoa, contudo, na fase inaugurada nos anos 1990, parece ser estendida também agora às "pessoas morais", ou seja, às instituições e aos indivíduos que, por força de investidura política, estão delas incumbidos. ${ }^{23}$ Conquanto o ponto abordado por Dupas diga respeito à sociedade da informação e à nova incerteza gerada pelas atitudes pós-modernas quanto à validade do conhecimento, sua análise pode ser transposta para o redimensionamento do campo historiográfico da política e das relações internacionais. Dupas recorre a Hans Jonas, de cujo Das Prinzip Verantwortung ( $O$ príncipio da responsabilidade ${ }^{24}$ ) utiliza a tradução francesa de 1990. Jonas desenvolve uma proposta de revisão do imperativo categórico "subjetivo" de Kant, que pode ser assim resumida: "Age de tal forma que os efeitos da tua ação sejam compatíveis com a preservação de uma verdadeira vida humana na Terra". Jonas entendia ter proposto, dessa maneira, tanto uma regra universalmente aplicável, inclusive a governantes, quanto uma alternativa viável ao "princípio esperança" de Ernst Bloch (Das Prinzip Hoffnung, 1954-59) que considerava ser utópico. Dupas combina o princípio da responsabilidade com o da realidade: a responsabilidade do homem de Estado deve ter presente, levar em conta a "causa da coletividade". Essa coletividade pode ser vista, certamente, em níveis diversos. Isso valeria tanto para o universo micro-cultural imediato de cada pessoa quanto o macro-cultural das relações interestatais no tempo e no espaço. Assim se pode entender a maneira de ver sua função por H. Védrine, referida acima.

\section{Antecedentes do problema ético nas relações internacionais desde finais do século 19}

Fiquemos com os fatos, mesmo se considerarmos com alguma desconfiança crítica o otimismo progressista, tardiamente herdeiro do pensamento oitocentista. Não se pode deixar de reconhecer que a assim chamada moralidade nas relações internacionais não é novidade plena nos anos 1990. É plausível considerar que teve pelo menos quatro grandes manifestações desde o final do século 19 até o período imediatamente após a $2^{\mathrm{a}}$ Guerra Mundial. Por certo vê-se, na fase iniciada após a queda do muro de Berlim e no impacto de seu valor simbólico sobre o conjunto das 
relações internacionais, uma modificação de grau e de intensidade. De uma parte, a questão da impessoalidade, da publicidade e da eticidade do agir político disseminouse por toda a escala social, deixando o que se poderia chamar de gueto acadêmico ou pastoral. De outra, a presença constante e crescente do tema no discurso mediático, no discurso político e na linguagem comum emprestou à questão da moralidade pública um grau de relevância social muitíssimo maior do que um mero artifício de retórica camuflador.

O primeiro exemplo de antecedente que cabe ser lembrado é o do Congresso de Berlim (1878). Liderado por dois cínicos notórios, Bismarck e Disraeli, o conclave tratou da questão dos Bálcãs em termos morais, sem hesitar contudo em partilhar a África como se fosse um loteamento de subúrbio e entregar Chipre à Grã-Bretanha como uma espécie de gorjeta. O vocabulário moralizante (pacificador, mantenedor do equilíbrio) aparece com força. Um segundo exemplo consiste nos quatorze pontos de Woodrow Wilson, cujo teor filosófico evidencia claramente a pretensão ético-política da ordem mundial das negociações. Se muitos dos pontos expressavam claramente a ideologia da economia liberal, a preocupação com o estatuto colonial, com a questão das nacionalidades e com o mecanismo da negociação (idealizado na Liga das Nações) põe a ordem mundial, mesmo se limitadamente, na perspectiva da moralidade.

Um terceiro exemplo, ordenado na mesma direção, é o do pacto de Paris de 27 de agosto de 1928 - conhecido pelos nomes de Aristide Briand e de Frank Kellogg, ministro francês das Relações Exteriores e secretário americano de Estado, respectivamente - cuja idéia-força da substituição definitiva do conflito armado pela negociação em ágoras políticas se origina no postulado ético do respeito à vida e aos direitos humanos, ao menos em tese. O princípio da arbitragem como regra de relacionamento internacional em qualquer tipo de disputa, embora não imediatamente bem sucedido, insere-se lenta e gradativamente no processo político mundial, primeiro em questões menores e sobretudo depois da superação da guerra fria.

Um quarto exemplo digno de menção é a própria Declaração Universal dos Direitos Humanos, da ONU, aprovada em 1948. Como em suas ilustres predecessoras da Virgínia em 1776 e de Versalhes em 1789, os postulados da dignidade inerente e dos direitos iguais e inalienáveis de todos os "membros da família humana" (Preâmbulo) ${ }^{25}$, expressos pela liberdade, pela justiça e pela paz no mundo, são enunciados de cunho tipicamente ético. A definição de postulados, de que decorram obrigações de comportamento, sejam elas particulares ou universais, privadas ou públicas, é necessariamente de natureza ética. A proclamação que precede o enunciado do art. $1^{\circ}$ da Declaração, logo após o preâmbulo, o mostra sobejamente. $\mathrm{O}$ revestimento jurídico dos enunciados não lhes retira o caráter moral e o formato, se não coercitivo, pelo menos indutivo de modos de agir. Pelo 
contrário, como insiste Casanova, a questão ética não pode ser dissociada da questão do direito.

\section{A referência ética no(s) direito(s)}

A questão é, porém, espinhosa: quem define o que é moral? Há valores universais ou somente valores particulares, próprios a cada continente, a cada civilização? A definição das normas éticas é neutra ou camufla interesses estratégicos ou econômicos? O direito internacional acabará por constituir o mesmo tipo de referência para a sociedade internacional - se é que existe uma sociedade assim - como o é o direito interno que rege as sociedades nacionais?

Cabe registrar a necessidade de um cuidado especial. Não se deve considerar que moral tenha um conteúdo necessário de origem ou viés religioso, por exemplo. Inercialmente, a história das sociedades humanas mostra que o comportamento moralmente relevante teria sempre uma vinculação imediata com mandamentos de fé religiosa. Essa convicção é ainda extremamente difundida. Desde o Iluminismo, porém, e em particular desde a sistematização do imperativo categórico segundo o formato kantiano, a moral deixou de estar necessária ou supostamente subordinada à arquitetura valorativa de uma religião. A relação da norma ética, no caso da ação política, se estabelece em termos de imperativo hipotético. A consecução de determinados fins - sejam eles referentes a direitos da pessoa humana e do cidadão, sejam vinculados à obtenção de metas estratégicas (políticas, econômicas, militares ou o que mais for) - se submete, por força de convênio, contrato ou acordo, a regras. Assim, se tal ou qual fim deve ser obtido, tais ou quais regras devem ser aplicadas. Essa foi a lógica que presidiu à sucessiva elaboração das convenções de Genebra respeitantes aos prisioneiros de guerra. Em suas seis grandes fórmulas, as convenções recorreram (por certo a posteriori) ao imperativo moral de tipo hipotético do seguinte tipo: se a dignidade da pessoa humana deve ser respeitada em um nível mínimo (dadas as circunstâncias de qualquer maneira desviantes do conflito bélico), então formas convencionadas de tratamento de prisioneiros hão de ser praticadas. Se o caráter beneficente (ou caritativo) da ótica de Henri Dunant, fundador da Cruz Vermelha Internacional, está na origem desse movimento 'moralizante', resta que o traço ético está presente - e é constante - mesmo na realidade conflituosa do mundo em guerra.

Um certo grau de tensão entre o quadro referencial do direito e a alegação ética ainda persiste. Uma coisa não é necessariamente co-extensiva com a outra. Casanova considera no mínimo duvidoso ver como um progresso decisivo do direito as decisões tomadas pelo Conselho de Segurança da ONU no caso das intervenções no Iraque e na ex-Iugoslávia. Os enunciados libertários ou moralistas de que se revestiram as decisões mal escondem os objetivos políticos e econômicos dos Estados 
Unidos e dos demais membros permanentes do Conselho, cuja ação foi diretamente viabilizada por outros membros, para chegar-se à maioria requerida. $\mathrm{O}$ ideal de uma ordem harmonicamente negociada por parceiros equivalentes, mais propriamente classificável no campo das utopias, é assim posto em dúvida por Casanova, mas defendida - em termos morais e de missão ética - por François Fillon, ex-ministro francês da cooperação internacional, que afirma: "Há séculos, a violência e a justiça, o realismo e a ética, a lógica dos interesses particulares e das exigências universais, forjam a dialética complexa do jogo internacional. Hoje, a cultura do direito internacional parece impor-se. Mesmo se o processo que levou a essa afirmação do jurídico não tenha começado apenas ontem, representa um ponto alto da tomada de consciência progressiva dos interesses convergentes dos povos e das nações". ${ }^{26}$

Essa consciência pública conjuga três parâmetros políticos e mentais de cunho ético. Em primeiro lugar, o parâmetro da memória, cristalizado em torno das tragédias que marcaram o século 20 e que forjaram a matriz analítica da historiografia ocidental (em particular a posterior a 1945). ${ }^{27} \mathrm{O}$ segundo parâmetro é o esgotamento das ideologias excludentes e das políticas radicais da negação da diferença e da alteridade. ${ }^{28} \mathrm{O}$ terceiro parâmetro diz respeito à sociedade da informação e da interdependência que emerge sob o signo da globalização tutelada. ${ }^{29}$ Acresce a estes um fator social de monta: a opinião pública expressa por três grandes meios. De início deve-se recordar os meios de comunicação social - dentre os quais se destaca particularmente a imprensa de opinião. Em seguida, cabe lembrar o papel crescentemente desempenhado pela organização espontânea da assim chamada sociedade civil, acentuado e acelerado na segunda metade do século 20 e diretamente reforçado pelas dificuldades não escamoteáveis da gestão econômica e financeira das relações interestatais, até o presente domínio reservado da ação intergovernamental.

Fillon reiteradamente volta a dois conceitos, ao qualificar o comportamento político internacional: o de egoísmo e o de cinismo. É certo que a busca dos objetivos próprios a determinado estado ou à constelação de seu(s) aliado(s) continuamente privilegiou um sistema decisório autocêntrico. A gênese mesma do sistema de poderes no mundo ocidental, em particular, deu-se sob a lógica da centralização individual ou dinástica, estatal e territorial, cujo fio condutor foi a mecânica das alianças contrabalanceadoras das ameaças próximas e o instrumento executivo da guerra. A gestão da memória dessa lógica, prevalente, no mundo moderno, desde as guerras de religião e pelo menos até o fim da $2^{\text {a }}$ Guerra Mundial (e em sua extensão sob a modalidade "fria"), pode ser exemplificada também pelos tratados que deram origem à União Européia. Uma das iniciativas mais diretamente inspiradas pela cesura do mundo foi a proposta de uma comunidade européia de defesa, formalizada no tratado de Paris de 1950, de iniciativa francesa. Pivô de grandes 
resistências alemãs (vencidas a duras penas) e de oposição aberta por parte da Grã-Bretanha, o tratado acaba por não ser ratificado pela própria Assembléia Nacional Francesa, em 1954.

Assim, o tratado de Roma, que instituiu a Comunidade Européia, mantém, desde 1957, em todas as suas versões, o objetivo de promover "sem cessar a união sempre mais estreita entre os povos europeus", de "eliminar as barreiras que dividem a Europa", de "consolidar ... as salvaguardas da paz e da liberdade, apelando aos outros povos da Europa que compartilham seu ideal a associar-se a seu esforço". ${ }^{30}$ Durante três décadas, as Comunidades Européias forneceram a prova enquadrada pelos "Trinta Gloriosos" e pela lógica da guerra fria - que as iniciativas econômicas, financeiras e comerciais podiam dar certo como fórmula de integração. ${ }^{31}$ A lógica da aliança entre economia e política não é nova. Na segunda metade do século 20 ela era plenamente reconhecível. Para o período que se inicia com o armistício de 8 de maio de 1945, pode-se lembrar dois marcos iniciais, que dão o tom: o discurso de 5 de junho, do Secretário de Estado americano, George C. Marshall, que apresenta o plano de ajuda à reconstrução da Europa e a instituição da Organização Européia de Cooperação Econômica (OECE), em 16 de abril de 1946. Em ambos os casos, constata-se que as ações se produzem por iniciativa direta ou instigação dos Estados Unidos. A diminuição do ritmo da prosperidade regular ao final dos anos 1970 suscitou crítica crescente ao que se passou a chamar de 'déficit democrático'. Entende-se por essa noção a ausência de participação social direta nos processos decisórios das Comunidades. Critica-se o caráter (entrementes menos marcado, mas ainda predominante) estritamente interestatal e intergovernamental da arquitetura das Comunidades. O fundamento dessa crítica está em um requisito ético, proclamado pelos analistas do processo de integração européia, como Pfetsch ${ }^{32}$ e Moravscik, ${ }^{33}$ por exemplo, de que a exclusão do cidadão e de seus direitos originários em titular da soberania representaria uma distorção da legitimidade ética das decisões tomadas e cuja observância é exigida. A primeira decisão prática, porém, foi interestatal e intergovernamental - como continua sendo mesmo depois do Tratado de Nice, de 26 de fevereiro de 2001 - foi a de promover eleições diretas para o Parlamento Europeu, que vieram a ter lugar em 1979. ${ }^{34}$ O relator do projeto de convenção européia sobre essa eleição, o deputado holandês Schelto Patijn, frisou - em 1975 - que tal iniciativa se destinava a enraizar profundamente o processo de unificação européia nos povos nele engajados, conferindo assim às Comunidades uma legitimidade que lhes faltava, parcialmente, até então. A percepção dos limites dessa iniciativa fica clara quando o relator se refere aos povos "engajados". O realismo político transparece nessa menção, na medida em que o apelo formal dos tratados aos "povos europeus" em geral não encontrava ainda tradução viável no espaço geopolítico do continente, mas apenas no das Comunidades reunindo, nessa data, nove países. 
O Tratado da União Européia, que deriva do tratado de Roma sobre a comunidade européia (1957), na forma adotada em Maastricht (1992), modifica o artigo $\mathrm{F}$, numerado como $6^{\circ}$, da maneira seguinte:

\begin{tabular}{|l|l|}
\hline \multicolumn{1}{|c|}{ Artigo F (Roma) } & Artigo 6 ${ }^{\circ}$ (Maastricht) \\
\hline $\begin{array}{l}\text { 1. A União respeita a identidade } \\
\text { nacional de seus estados-membros, } \\
\text { cujos sistemas de governo se } \\
\text { fundam nos princípios } \\
\text { democráticos. }\end{array}$ & $\begin{array}{l}\text { 1. A União se funda nos princípios da } \\
\text { liberdade, da democracia, do respeito } \\
\text { dos direitos do homem e das } \\
\text { liberdades fundamentais, assim como } \\
\text { no estado de direito, princípios que são } \\
\text { comuns aos estados-membros. }\end{array}$ \\
\hline $\begin{array}{l}\text { 2. A União respeita os direitos } \\
\text { fundamentais, tais como garantidos } \\
\text { pela Convenção européia de } \\
\text { salvaguarda dos direitos do homem } \\
\text { e das liberdades fundamentais, } \\
\text { assinada em Roma em 4 de } \\
\text { novembro de 1950, e tais como } \\
\text { resultam das tradições } \\
\text { constitucionais comuns aos estados- } \\
\text { membros, enquanto princípios gerais } \\
\text { do direito comunitário. }\end{array}$ & $\begin{array}{l}\text { 2. A União respeita os direitos } \\
\text { fundamentais, tais como garantidos } \\
\text { pela Convenção européia de } \\
\text { salvaguarda dos direitos do homem e } \\
\text { das liberdades fundamentais, assinada } \\
\text { em Roma em 4 de novembro de 1950, } \\
\text { e tais como resultam das tradições } \\
\text { constitucionais comuns aos estados- } \\
\text { membros, enquanto princípios gerais } \\
\text { do direito comunitário. }\end{array}$ \\
\hline $\begin{array}{l}\text { 3. A União se dota dos meios } \\
\text { necessários à consecução de seus } \\
\text { objetivos e à implementação de } \\
\text { suas políticas. }\end{array}$ & $\begin{array}{l}\text { 3. A União respeita a identidade } \\
\text { nacional de seus estados-membros. }\end{array}$ \\
\hline
\end{tabular}

Vê-se que, entre o final da década de 1950 e o início da década de 1990, o conjunto dos estados-membros da União Européia incorporou uma hierarquia de valores que trouxe nova orientação para a seqüência do processo decisório. A alínea 1 do art. $6^{\circ}$ de Maastricht faz passar à frente da versão anterior uma visão 
supranacional, se não universalista. A referência precedente, de cunho nacional, prevalece no momento inicial. A explicitação do critério ético dos direitos entrementes veio a ser alçada à posição de destaque. A identidade-diretriz dos estados fundadores passa à terceira alínea, como referência - entrementes histórica - mas não mais como princípio norteador.

O princípio norteador se exprime, pois, em duas vertentes: os direitos e liberdades do homem, de uma parte, e a democracia liberal, de outra. A menção ao sistema de governo, ainda presente em 1957, deixa de ser entendido como necessária após a queda do muro de Berlim e ao reordenamento das relações políticas internacionais. É, contudo, útil lembrar que se há evolução perceptível no plano político, a questão econômica e comercial, tanto interna quanto externamente à União, segue problemática. Boa parte do "euroceticismo", sobretudo entre britânicos e escandinavos, advém do fato de haver fortes diferenças culturais, de um lado, mas também, e sobretudo, das complexas diferenças econômicas e financeiras.

É fato que a preocupação com um ordenamento de princípios e da subordinação da lógica decisória à hierarquia desses princípios ocupa (e preocupa) os espíritos desde o fim da experiência (já então assustadora) da $1^{\mathrm{a}}$ Guerra Mundial. Aléxis Leger, em memorando ao governo francês, datado de $1^{\circ}$ de maio de 1930 , detém-se longamente em um programa de instituição de uma união federal européia, cujo primeiro item é intitulado: "Necessidade de um pacto de ordem geral, por elementar que seja, para afirmar o princípio da união moral européia e consagrar solenemente o fato da solidariedade instituída entre estados europeus." ${ }^{35} \mathrm{O}$ memorando, repleto de indicações e sugestões que hoje podem ser reconhecidas em inúmeras regras e práticas da União Européia, estava colocado na perspectiva - otimista - da Sociedade das Nações. ${ }^{36}$

Ora, o apelo político só fez expandir-se desde então. Zorgbibe recorda que não faltou quem estabelecesse paralelos com o movimento revolucionário de 1789 e com o juramento do Jeu de Paume e a auto-investidura de facto do poder constituinte por parte dos revoltosos. Lembra também que houve vozes que contrastaram essa perspectiva otimista de moralização política com a realidade de a ruptura institucional do Antigo Regime não coincidir diretamente com o conceito de soberania popular próprio ao enciclopedismo. ${ }^{37}$ Entretanto o vínculo com um fundamento ético, particularmente com relação ao caráter social, contratual, convencional das relações intranacionais e internacionais, no sentido da convergência, da solidariedade e da subsidiaridade, é elemento permanente da retórica governamental e dos textos fundantes. Esses componentes são o eixo organizador da prática democrática em si, para além da teoria da democracia em tese. Bastante cedo - para o mundo contemporâneo - o Conselho da Europa, primeira organização européia cujo objetivo era a cooperação política, proclama sua adesão inabalável aos "valores espirituais e morais que estão na origem dos 
princípios de liberdade individual, de liberdade política e de preeminência do direito, sobre os quais se funda a verdadeira democracia". ${ }^{38}$

A especificação concreta da democracia se faz, obviamente, nos textos constitucionais de cada estado. Embora os tratados europeus e seus desdobramentos apareçam, a cada vez, como uma "constituição cumulativa", a União Européia não tem, formalmente, uma carta magna. A institucionalização, a estatização mesmo, poder-se-ia dizer, é uma prioridade tal que a edição européia do prestigioso semanário The Economist (vol. 357, $\mathrm{n}^{\circ}$ 8194, 28.10-3.11.2000) publica um editorial (pp. 1112) e um pré-projeto de carta constitucional para a Europa (pp. 21-28). De recorte claramente estatal e interestatal, a proposta tem o mérito - sobretudo no mundo anglo-saxão - de colocar na mesa a irreversibilidade história do processo de integração européia e o caráter paradigmático que assumiu desde 1950: “... efforts to devise a constitution for the European Union would encourage a searching examination of ideals and purposes, which would be splendid". Na falta de uma "constituição européia" - cujo tema aparece, contudo, freqüentemente nas análises políticas e históricas, em especial desde o discurso de 12 de maio de 2000, do ministro alemão do Exterior, Joschka Fischer, em Berlim - Zorgbibe recorre à convenção européia para a proteção dos direitos humanos e das liberdades fundamentais, de 3 de setembro de 1953. ${ }^{39}$ Para Zorgbibe, ela realiza - pela primeira vez - a conjunção entre ética e poder definida por Georges Scelle. Professor de direito na universidade francesa de Dijon, Scelle escreveu dois opúsculos, em 1922 e 1923, nos quais exalta a moralização das relações interestatais e o papel desempenhado pela Sociedade das Nações, na perspectiva do objetivo da obtenção e manutenção da paz como ambiente garantidor da realização pessoal e coletiva do cidadão. ${ }^{40} \mathrm{O}$ caráter ético da democracia se exprime na tomada de consciência da sociedade respectiva com relação à necessidade de reconhecer os direitos fundamentais da pessoa humana. $\mathrm{O}$ aspecto do poder aparece na proclamação da necessidade de instituir e manter mecanismos de controle e de sanção que darão aos direitos eficácia, evitando assim que se restrinjam a meras declarações retóricas de ética formal.

Zorgbibe constata que, na sociedade internacional, o reclamo ético parece preceder o poder. $\mathrm{O}$ meio social internacional percebe determinadas normas como fundamentais e o caráter essencial de certos comportamentos a serem exigidos dos estados (interna e externamente). Essa percepção, até meados dos anos 1980, parecia ser inócua ou vã, na medida em que o pretendido "realismo político" a ignorava. Os anos 1990 introduziram o tema da ética e da "ética na política" de forma aparentemente irreversível. Essa incontornabilidade do requisito ético já havia sido também percebida, aliás pragmaticamente, por um político francês de grande influência e de particular prestígio moral. André Malraux, ministro da Cultura da França de 1959 a 1969, escrevera em 1937, em $L^{\prime} E$ Espoir, ${ }^{41}$ que se não se faz política com a moral, tampouco se a pode fazer sem ela. 
A perspectiva que se abre à investigação histórica está na reconstrução dos caminhos que transformaram "idéias institucionalizadas", ${ }^{2}$ como as dos direitos humanos, por exemplo, em fator determinante das políticas internas e externas, e em sua consagração como instância "supra-política" de referência e de julgamento. Se esse é um percurso com pouco mais de duzentos anos de história, a segunda metade do século 20 e particularmente a década de 1990 viram-no entrar em um ritmo acelerado de validação das políticas argumentadas. E quando razões são exigidas, idéias são incontornáveis. E a sua história, indispensável.

\section{Notas}

1 Direitos Humanos. Brasília: Senado Federal, 1997, 2a . ed., vols. 1 e 2.

2 Cf. J. A. Lindgren Alves: A arquitetura internacional dos direitos humanos. São Paulo: FTD, 1997; Vicente Marotta Rangel: Direitos humanos e relações internacionais. São Paulo: Editora Revista do Tribunais, 2000, 6a. ed.

3 Cf. Eiiti Sato: A agenda internacional depois da Guerra Fria: novos temas e novas percepções, em Revista Brasileira de Política Internacional 43 (1), p. 138-169, 2000.

4 Cf. Ana Flávia Barros-Platiau e Marcelo Dias Varela: A percepção da soberania brasileira face a questões emergentes na agenda internacional, em Carta Internacional 96, p. 7-10, 2001.

5 J. A. Lindgren Alves: A cúpula mundial sobre o desenvolvimento social e os paradoxos de Copenhague, em Revista Brasileira de Política Internacional 40 (1), p. 142-166, 1997.

6 Cf. Celso Lafer: Comércio, desamarmento, direitos humanos. São Paulo, Paz e Terra, 1999.

7 Cf. Benoni Belli: O fim da guerra fria: algumas implicações para a política externa brasileira, em Revista Brasileira de Política Internacional 39 (1), p. 120-131, 1996.

8 The Anarchical Society: A Study of Order in World Politics, Nova Iorque, 1977.

9 Cf. International Law em Joel Krieger (ed.): The Oxford Companion to Politics of the World. Nova Iorque/Oxford: Oxford University Press, 1993, pp. 440-444, esp. 443-444.

10 George F. Kennan: Morality and Foreign Affairs, em Foreign Affairs 64 (Winter 1985/86), p., 206, apud David A. Lake em Krieger (ed.), op. cit., p. 773.

11 Hans Morgenthau: Another 'Great Debate': The National Interest of the United States em American Political Science Review 46 (1952) 988, apud Lake em Krieger (ver nota anterior).

12 Cf. a esse respeito José Antonio Giusti Tavares. Sistemas eleitorais nas democracias contemporâneas: teoria, instituições, estratégias. Rio de Janeiro: Relume-Dumará, 1994.

13 Cf. Georges-Henri Soutou: La guerre de Cinquante Ans. Le conflit Est-Ouest 1943-1990. Paris: Arthème Fayard, 2001; Ch.-O. Carbonell (org.): Une histoire européenne de l'Europe. Toulouse: Privat, 1999, 2 vols.; E. Nolte: Der europäische Bürgerkrieg 1914-1945. Viena/Colônia: Böhlau, 2001, $3^{\text {a }}$ ed. rev.; W. Lippmann: The Cold War: A Study of the United States Foreign Policy. Nova Iorque, 1947; John Lewis Gaddis: Rethinking Cold War History. Oxford: Clarendon Press, 1997.

14 Cf. edição da Academia das Ciências da Prússia (Berlim), vol. IV, p. 385-464, esp. p. 399-400. Ed. fac-similar: Berlim: de Gruyter, 1968.

15 A. Watson: The evolution of international society. Londres/Nova Iorque: Routledge, 1992, p. 299.

16 Hubert Védrine: Moralisation des relations internationales: pour une synthèse de l'expérience historique, du réalisme et des exigencies morales, em Pascal Boniface (org.): Morale et relations internationales. Paris: IRIS/PUF, 2000, p. 19-23, esp. p. 22. 
17 Jean-Claude Casanova. Moralisation des relations internationales et progrès du droit?, em Boniface: op. cit., pp. 31-33.

18 Folha de São Paulo, edição n ${ }^{\circ} 26.401,15.7 .2001$, p. A 2.

19 François Fillon: Les instruments de la morale internationale, em Boniface, op. cit., p. 35.

20 Cf. Le Portugal et le nouveau défi de l'Europe, em Ariane Landuyt (org.): Europe: fédération ou nations. Paris: SEDES, 1999, pp. 191-204.

21 Op. cit., p. 300.

22 Gilberto Dupas: Ética e poder na sociedade da informação. São Paulo: Editora UNESP, 2000.

23 Dupas, op. cit., p. 91-92.

24 Das Prinzip Verantwortung. Versuch einer Ethik für die technologische Zivilisation. Frankfurt: Suhrkamp, 1989 (ed. orig. 1979).

25 Universal Declaration of Human Rights, 1948, em: Ian Brownlie (ed.): Basic Documents in Human Rights. Oxford: Clarendon Press, 1994 (3a. ed., 2a. reimpr.), pp. 21-27.

26 L'importance du droit ne doit pas masquer le role de la politique, em: Boniface, op. cit., p. 45.

27 Cf. Jean-Baptiste Duroselle: L'Europe. Histoire de ses peuples. Paris: Hachette/Pluriel, 1998 (ed. original: 1990); Saul Friedlaender: Geschichte des deutschen Judentums. Munique: Oldenbourg, 1997; Nazi Germany and the Jews: The Years of Persecution 1933-1939 e (ed.) Probing the Limits of Representation: Nazism and the Final Solution e ainda When Memory Comes;.François Bédarida: Le nazisme et le génocide. Paris: Pocket, 1997 (ed. de bolso).

28 Cf. Estevão de Rezende Martins: A ideologia morreu, viva a ideologia, em Humanidades; e Direitos humanos em perspectiva histórica. Elementos de uma teoria multiculturalista comparativa, em Jessé Souza (org.): Multiculturalismo e racismo. Brasília: Paralelo 15, 1997, p. 171-188.

29 Manuel Castells. The Power of Identity. Malden: Blackwell, 1997.

30 Cf. edição da La documentation française: Les traités de Rome, Maastricht et Amsterdam, Paris: 1999, p. 45-46.

32 Frank R. Pfetsch: Die Europäische Union. Geschichte, Institutionen, Prozesse. Munique, UTB, 1997. Trad. bras. por Estevão de Rezende Martins. Brasília: Editora Universidade de Brasíli, 2001.

33 A. Moravscik: The Choice for Europe: Social Purpose and State Power from Messina to Maastricht. Londres: UCL Press, 1998; cf. também Preferences and Power in the European Community: A Liberal Intergovernmentalist Approach, em Journal of Common Market Studies 31 (1993).

34 Giuseppe Mammarella (Storia d'Europa dal 1945 a oggi. Roma-Bari: Laterza, 1999, $3^{\text {a }}$ ed.) lembra, a propósito dessa eleição inaugural, seu caráter de recuperação da ação européia, após uma fase em que "troppi interessi particolari avevano paralizzato o ritardato l'attività delle organizzazioni europee ...." (p. 484).

35 Memorando transcrito em Zorgbibe, op. cit., p. 8-14. Para esta passagem, ver p. 8.

36 Memorando Leger, item I, $3^{\circ}$ parágrafo: "Il emporterait en effet de definir le caractère de l'Europe, considérée comme une entente régionale répondant aux dispositions de l'article $21 \mathrm{du}$ Pacte de la SDN et exerçant son activité dans le cadre de la SDN." Cf. nota 21; p. 8 [grifos meus].

37 Charles Zorgbibe. Histoire de la construction européenne. Paris: Presses Universitaires de France, 1997, $2^{\text {a }}$ ed., p. 236.

38 Estatuto de 5 de maio de 1946, adotado em Londres. O Conselho da Europa não é dotado de instrumentos eficazes de ação.

39 A assinatura dessa convenção remonta a 4.11.1950, mas Zorgbibe prefere utilizar a data de vigência.

40 Cf. L'Oeuvre politique de la Société des nations (1920-1923). Paris: PUF, 1922 e 1923.

41 Paris: Gallimard, 1948. 
42 Cf. Judith Goldstein e Robert O. Keohane (orgs.): Ideas \& Foreign Policy. Beliefs, Institutions and Political Change. Ithaca/Londres: Cornell University Press, 1993. Ver esp. a introdução, p.23.

\section{Resumo}

As relações internacionais passaram a refletir, em ritmo crescente, a partir dos anos 1990, a exigência de moralização do espaço público. O tema da ética, já presente na agenda política interna, é incorporado no programa de ação dos organismos multilaterais e cobrado cada vez mais intensamente dos agentes políticos. Nos campos interno como externo a agenda ética contemporânea articula-se sobretudo em torno dos direitos humanos, como pauta de valores comportamentais válida de igual forma para indivíduos e coletividades, inclusive as politicamente institucionalizadas. Disso dão exemplo a política interna e externa brasileira, a tendência organizacional dos blocos regionais, como a União Européia, e a "cláusula social" tornada indispensável às relações econômicas, comerciais e financeiras.

\section{Abstract}

The international relations began to reflect more intensively since the $1990 \mathrm{~s}$ the requirement of moralization of the public sphere. The theme of ethics - often present on the internal political agendas - gets into the action programs of multilateral organizations and becomes strongly requested from public agents. On the internal and external field as well the contemporary ethical agenda takes the human rights as its substantial reference, as the leading values for a valuable private and public behavior, including the international organizations. For such a historical trend some examples may be mentioned: the internal and external Brazilian policy on human rights, the organizing tendency of the regional blocks, as the European Union, and the "social clause" considered as indispensable to the economic, commercial and financial relations.

Palavras-chaves: Ética. Direitos humanos. Agenda moral. Política internacional. Key words: Ethics. Human rights. Moral agenda. 